\title{
I am the Ocean - arts and sciences to move from ocean literacy to passion for the ocean
}

\begin{abstract}
Recent events in world politics demonstrate that a part of society has lost faith in their institutions. The importance of facts and evidence in citizens' decision making is weakened by opinions and belief systems. This post-fact or alternate facts era is a new challenge in the field of science communication as we urgently need to tackle global environmental challenges. Not only do scientists need to better communicate their work, they also need to explore alternative ways of transferring knowledge to help citizens reconnect with nature and actively take responsible decisions to protect it. The activity 'I am the Ocean' has been developed by an artist and a scientist with the goal to help students understand, connect and be equipped to take actions on marine global changes. The activity was a mix of field trips, open discussions and sensory immersion. It illustrates how art and metaphors can add an emotional and physical dimension to science communication, allowing a better understanding of otherwise invisible threats, and move from knowledge to passion.
\end{abstract}

Submitted 1 March 2017; accepted 1 March 2017; first published online 28 March 2017

\begin{abstract}
'Don't make the mistake of thinking the arts and sciences are at odds with one another. That is a recent, stupid, and damaging idea. (...) The arts and sciences need to work together to improve how knowledge is communicated.' (Tim Minchin, 2013)

The Ocean is under unprecedented local and global challenges (IPCC, 2013). This increasing destruction and pollution subsequently threatens humankind by putting at risk the countless services provided by marine ecosystems. In the face of global changes such as warming and ocean acidification, only collective actions can lead to the needed mitigation and adaptation measures. These will necessitate public understanding of both the marine realm and global changes as well as a strong will to act upon challenges or accept the required political and economic changes. This is a real challenge as many features of the ocean are difficult to experience because they are too small, too big or too abstract. When it comes to global changes, we are also faced with concepts that are somewhat difficult to comprehend. These can be invisible, geographically or temporally distant, and it is then tempting to ignore them. This led to the increasing interest around the world in developing citizens' ocean literacy, the 'understanding of the ocean's influence on you and your influence on the ocean' (Cava et al., 2005). Being ocean literate implies being able to address marine issues in order to develop solutions and actions adapted to our culture and values (Dupont \& Fauville, 2017). Working closely with educators and communicators, scientists can play a key role in
\end{abstract}

Email: sam.dupont@bioenv.gu.se moving toward a more ocean literate society. For this purpose, scientists need to be better trained in various form of communication, including strategies derived from psychology, sociology and have a deeper understanding of stakeholders' cultures (Dupont et al., 2015). There may also be a need for more fundamental changes in the way science is performed. For a more effective form of scientific communication, we may need to deviate from the linear science supply paradigm and rather produce some science directly targeting societal values (e.g. Dupont et al., 2014, 2015).

Being more ocean or environment literate does not necessarily translate into positive actions. For example, Kahan et al. (2012) showed that increased science literacy did not lead to consensus but promoted more polarization on climate change issues. The reason behind this gap between environmental knowledge and pro-environmental behaviour can be attributed to many external and internal parameters. However, emotional involvement is often identified as a key factor shaping environmental awareness and attitude (see Kollmuss \& Agyeman, 2002 for review).

One of the characteristics of the arts is their ability to evoke emotions. Art can provide an open forum where science, nature and society can reconnect, working on our senses, emotions and values. Scientists who are exposed to art to communicate their science generally agree that it creates a constructive atmosphere, an alternative way of sharing their knowledge, including a simpler way to explain complex scientific concepts, as well as an opportunity to self-reflect (Curtis et al., 2012). When successfully combined, arts and sciences can lead to self-realization and reflection as well as a will to take actions. As an example, the artist Chris Jordan made a 
picture inspired by a watercolor painting by Sarah Miller. This $64^{\prime \prime} \times 94^{\prime \prime}$ piece viewed from a distance represents two sharks. Closer inspection reveals that it is made of 270,000 fossilized shark teeth corresponding to the number of sharks killed every single day for their fins (Worms et al., 2013). This provides a visual understanding of the enormity of this number and can be a first step toward a better understanding of the issue.

To explore the idea that the arts and sciences can help to physically and emotionally connect citizens to marine global changes and to lead to an effective way to drive and support the required collective actions, I (as a marine biologist) teamed up with the artist (musician, poet, adventurer) Henrik Wallgren. We worked in the context of a European project coordinated by Maria Mebius Schröder from TILLT (http://www.tillt.se/en-GB) and funded by the Swedish Institute. The aim was to combine the arts and sciences to facilitate knowledge transfer and increase awareness and values about the marine environment in young citizens. We designed a two half day activity that was tested on 32 high school students from the Donnergymnasiet school (Gothenburg) and presented to marine communicators in November 2016.

Our approach was to use sensory immersion as a way to create a strong connection between the ocean, global change science and individuals. We combined guided discussions with field trips. Discussions encourage critical thinking, scepticism and allow students to take ownership of ideas and arguments and are also a way to develop a personal connection with a topic (Zeidler, 1997). Field trips promote contact with the ocean and are postulated to have a positive impact on specific aspects of learning (e.g. Ramasundaram et al. 2005). For example, Stepath (2006) showed that a field trip

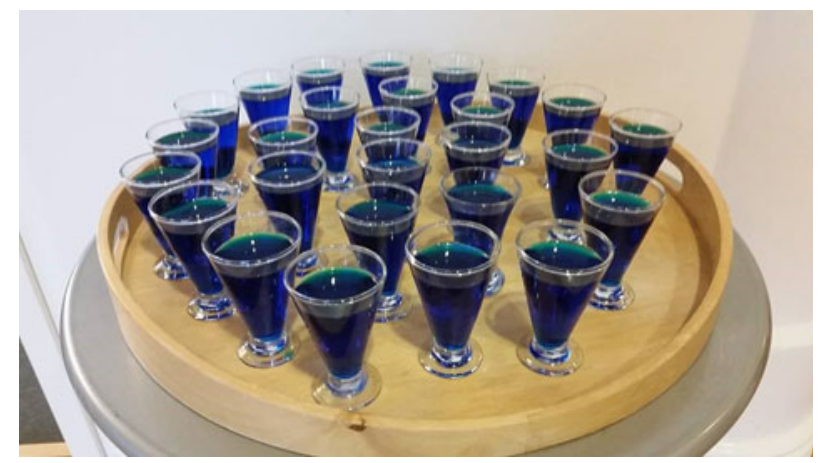

Fig. 1. The blue shot experiment: 'You take the blue pill - the story ends, you wake up in your bed and believe whatever you want to believe. You take the red pill - you stay in Wonderland, and I show you how deep the rabbit hole goes' (Morpheus in The Matrix).

to a coral reef caused significant modification in high school students' environmental attitudes and intention to act.

The activity was divided into two parts. The first day, the students were asked to discuss and reflect on the role played by the ocean in their everyday life. This also included consideration of the many threats that humans pose on marine life. Students were then challenged to be the ocean for one week. As a first task as the ocean, they were asked to eat a mysterious red soup and pay attention to consequences on their body when back home. Alternatively, when presenting our activity during a lunch seminar, we asked the adult participants to be the ocean and blindly drink a 'blue shot' without knowing the content (Figure 1). The goal of this exercise was to give the participants a sense of the fact that the ocean is passively suffering from human pollution. The soup was a beetroot borscht
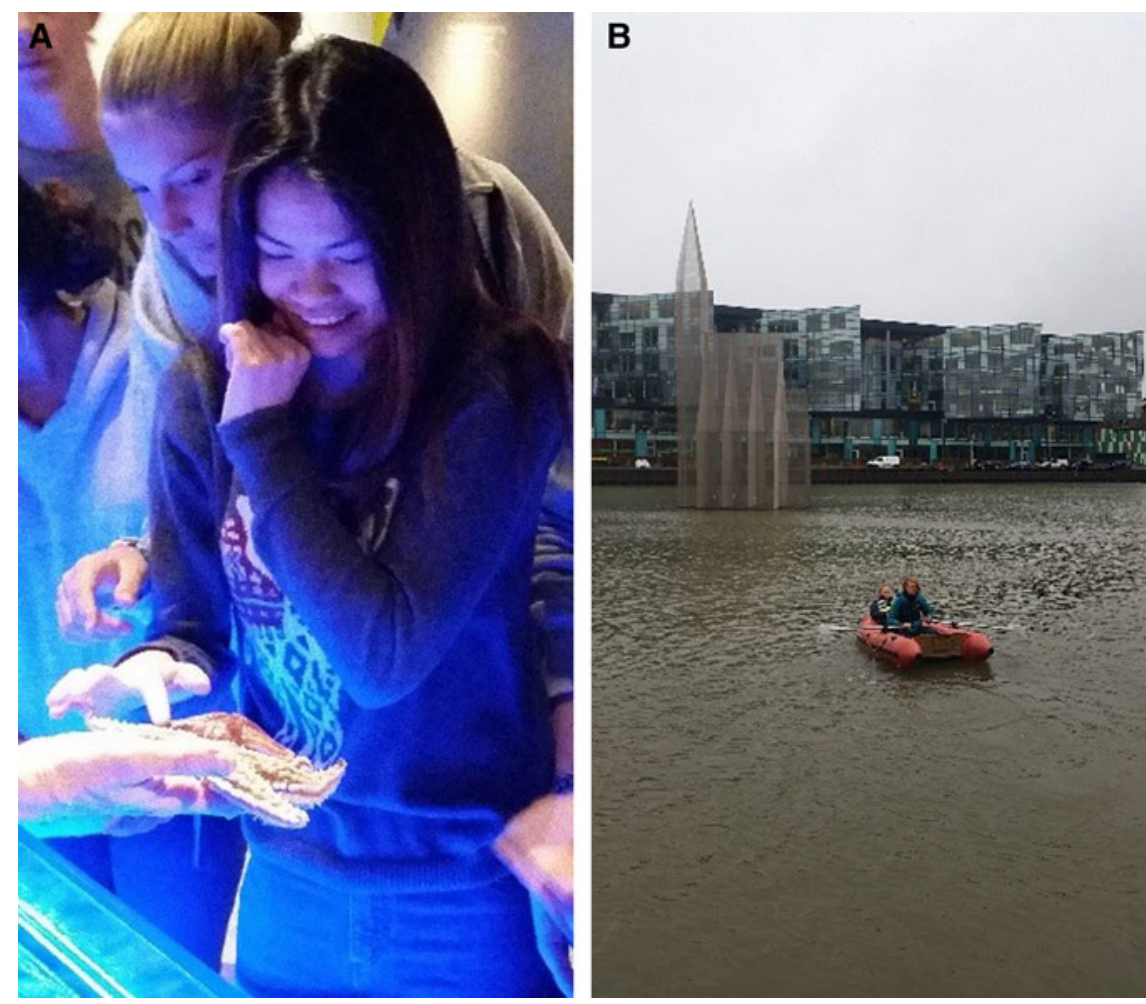

Fig. 2. I am the Ocean' activity. (A) Day 1, visit of the Aquarium of the Sjöfartmuseet in Gothenburg; (B) day 2, fishing for ideas. 
and the blue shot was water with a harmless food colouring. Eating beetroot soup caused the excretion of pigments that colour urine in red or pink. This was used as a sensory metaphor (fear of taking an unknown substance and/or observing the consequences on their own body) of the fact that pollution is not without consequences, a realization that the students had when back home and that was discussed at the beginning of the second day.

The second part of the first day of the activity was a 'behind the scene' tour of the Sjöfartmuseet Aquarium in Gothenburg (Figure 2A). Students had both a hint of the beauty of the ocean as well as a better understanding of the complexity that underlies good water quality and hence the health of marine life.

The second day focused on solutions. It started with a few outdoor activities where students had to brave the bad Swedish weather to go on a rowing boat and collect capsules containing solutions to global changes hanging on a structure in the middle of the harbour (Figure $2 \mathrm{~B}$ ). When back on land, they could open the capsule to discover that it only contained a blank page. For the rest of the activity, they were asked to work in small groups to fill up this page. They had to focus on what they care the most about in the ocean, reflect on what were the main associated threats and provide at least one solution each.

When asked what they cared about the ocean, only a minority of the students mentioned socio-economic services such as food or climate feedback. Most of them rather highlighted the inner beauty of the marine realm and the need to preserve it for future generations. They proposed many creative solutions from recycling to drastic lifestyle changes. However, the most inspiring aspect of the activity was the tangible passion inside the group. By combining a sense of wonder (e.g. the visit of the aquarium; Figure $2 \mathrm{~A}$ ), a physical realization of the impact we have (e.g. the blue shot experiment; Figure 1) and appropriation of problems and solutions (Figure $2 \mathrm{~B}$ ), all the participants, including the organizing team, were sharing a unique passion and will to act. Some students expressed their interest in becoming marine biologists or in starting actions at school and at home to decrease their carbon footprint.

Scientists have little time and often little academic reward for scientific communication. However, they often share with artists a real passion for their work. Taking the time and the risk to move out of our comfort zone to take the challenge of working with artists and students is a truly transformative experience and a step toward moving from ocean literacy to a real passion for the ocean.

A video summarizing the activity is available at: https:// www.youtube.com/watch? $=\mathrm{n}_{3}$ jcbcUG $3 \mathrm{LA}$.

\section{REFERENCES}

Cava F., Schoedinger S., Strang C. and Tuddenham P. (2005) Science content and standards for ocean literacy: a report on ocean literacy. Available at http://www.coexploration.org/oceanliteracy/documents/ OLit2004-05_Final_Report.pdf.
Curtis D.J., Reid N. and Ballard G. (2012) Communicating ecology through art: what scientists think. Ecology and Society 14, 3.

Dupont S. and Fauville G. (2017) Ocean literacy as a key toward sustainable development and ocean governance. In Handbook on the economics and management for sustainable oceans. Cheltenham: Edward Elgar Publishers \& UNEP, pp. 519-537.

Dupont S., Hall E., Calosi P. and Lundve B. (2014) First evidence of altered sensory quality in a shellfish exposed to decreased $\mathrm{pH}$ relevant for ocean acidification. Journal of Shellfish Research 33, 857-861.

Dupont S., Puncher G. and Calosi P. (2015) Bird is the word - on the importance of ethical and effective scientific communication. Journal of the Marine Biological Association of the United Kingdom 95, $863-864$.

IPCC (2013) Climate change 2014: impacts, adaptation, and vulnerability. Part a: global and sectoral aspects. In Fiels C.B., Barros V.R., Dokken D.J., Mach K.J., Mastrandrea M.D., Bilir T.E., Chatterjee M., Ebi K.L., Estrada Y.O., Genova R.C., Girma B., Kissel E.S., Levy A.N., MacCracken S., Mastrandrea P.R. and White L.L. (eds) Contribution of Working Group II to the fifth assessment report of the Intergovernmental Panel on Climate Change. Cambridge, UK and New York, NY: Cambridge University Press, pp. 1132.

Kahan D.M., Peters E., Wittlin M., Slovic P., Larrimore Ouellette L., Braman D. and Mandel G. (2012) The polarizing impact of science literacy and numeracy on perceived climate change risks. Nature Climate Change 2, 732-735

Kollmuss A. and Agyeman J. (2002) Mind the gap: why do people act environmentally and what are the barriers to pro-environmental behavior? Environmental Education Research 8, 239-260.

Minchin T. (2013) http://www.timminchin.com/2013/o9/25/occasionaladdress/.

Ramasundaram V., Grunwald S., Mangeot A., Comerford N. and Bliss C. (2005) Development of an environmental virtual field laboratory. Computers and Education 45, 21-34.

Stepath C.M. (2006) Coral reefs as sites for experiential environmental education: Learning with Australian students - a foundational study. Doctoral dissertation. James Cook University, Australia.

Worms B., Davis B., Kettemer L., Ward-Paige C.A., Chapman D., Heithaus M.R., Kessell S.T. and Gruber S.H. (2013) Global catches, exploitation rates, and rebuilding options for sharks. Marine Policy 40, 194-204.

and

Zeidler D.L. (1997) The central role of fallacious thinking in science education. Science Education 81, 483-496.

\section{Correspondence should be addressed to:}

S. Dupont

Department for Biological and Environmental Sciences, University of Gothenburg,

The Sven Lovén Centre for Marine Infrastructure Kristineberg, 45178 Fiskebäckskil,

Sweden

email: sam.dupont@bioenv.gu.se

Sam Dupont

Department for Biological and Environmental Sciences,

University of Gothenburg, The Sven Lovén Centre for Marine Infrastructure - Kristineberg, 45178 Fiskebäckskil, Sweden 